Article

\title{
A Study on Optimal Machining Conditions and Energy Efficiency in Plasma Assisted Machining of Ti-6Al-4V
}

\author{
Young-Hun Lee and Choon-Man Lee *(D) \\ School of Mechanical Engineering, Changwon National University, 20, Changwondaehak-ro, Uichang-gu, \\ Changwon 51140, Korea \\ * Correspondence: cmlee@changwon.ac.kr; Tel.: +82-55-213-3622; Fax: +82-55-267-1160
}

Received: 14 July 2019; Accepted: 12 August 2019; Published: 14 August 2019

\begin{abstract}
This research objective was to determine the significant parameters for effective plasma assisted machining (PAM) of Ti-6Al-4V and to derive optimal processing conditions. PAM parameters such as feed rate, spindle speed, and depth of cut have significant effects on its machining characteristic. In this study, the design of experiments (DOE) was used to select optimal machining conditions for PAM. The signal-to-noise $(\mathrm{S} / \mathrm{N})$ ratio was analyzed using the Taguchi method and the contributions of the factors were determined using analysis of variance (ANOVA). Finally, the optimal PAM machining conditions were selected using response optimization. In addition, the energy efficiency of conventional machining (CM) and the PAM were compared. The energy efficiency was analyzed by specific cutting energy. The cutting force and surface roughness of PAM decreased by $60.2 \%$ and $70.5 \%$, respectively, in optimal PAM machining conditions.
\end{abstract}

Keywords: plasma assisted machining; design of experiment; energy efficiency

\section{Introduction}

There has been a sharply increasing demand recently for difficult-to-cut materials in various industrial fields such as medical devices and aerospace. However, because difficult-to-cut materials have exceptional mechanical properties including high strength and abrasion resistance, they are difficult to machine using conventional machining (CM). For example, using $\mathrm{CM}$, tool life and machining quality decrease due to the high cutting force required [1-3]. Consequently, many researchers have been actively studying advanced methods for machining difficult-to-cut materials efficiently. One of these, thermally assisted machining (TAM), is attracting attention as an effective method. TAM is a machining method where difficult-to-cut materials are softened by an external heat source prior to engaging the cutting tool. Three types of TAM method have mainly been studied, according to the type of heat source: laser assisted machining (LAM), induction assisted machining (IAM), and plasma assisted machining (PAM). The most active study among these is LAM, where current research and LAM devices have been investigated [4,5]. The development of a control method of a complex tool path and the development of a high-performance tool were proposed as a future research direction. A thermal model was developed to calculate the temperature during the LAM [6-8]. Through the developed model, the thermal distribution of the workpiece was obtained and appropriate machining conditions were presented. Numerous research on the machinability of various difficult-to-cut materials have been conducted. Research has been carried out to improve the machinability of Inconel 718, which has high toughness $[9,10]$. A study was also conducted on the machining of brittle materials such as ceramics and glass [11-14]. Furthermore, hybrid processes that combine LAM and other processes have been proposed $[15,16]$. One TAM method, PAM, is more attractive commercially because it is 
lower in price than the LAM. In addition, since its spot size is larger than that of lasers, PAM has an advantage in the milling process. If an entire section is heated by a small spot, it creates a technical problem because the torch must be rotated at the same rotational speed of the cutting tool. On the other hand, the use of larger spots allows heating including all radial cutting depths, directly in front of the end mill [17].

In PAM, it is very important to study the proper conditions because cutting force and machining quality will vary depending on the machining conditions. PAM has various machining conditions such as feed rate, spindle speed, depth of cut, power, gas flow rate, torch angle, and so on.

Previous PAM research has been conducted with a focus on machining characteristics. Lopez de Lacalle et al. [17] analyzed tool wear and cutting force using PAM and established that PAM reduced the cutting force by $25 \%$ and increased productivity by $350 \%$. Moon and Lee [18] analyzed the cutting force and surface roughness of an AISI 1045 material using PAM and established that PAM reduced the cutting force and surface roughness by 61 to $15 \%$ and 79 to $5 \%$, respectively. Kitagawa and Maekawa [19] studied the tool wear and machinability of ceramic materials after applying a plasma heat source to the turning process. Lee et al. [20] studied the machining characteristics according to torch angle, by setting the plasma torch angle as a machining variable.

Studies on the preheating effect of PAM have also been carried out. Kim et al. [21] studied the preheating effect on cylindrical shaped specimens using PAM. Baek et al. [22] studied the preheating effect of laser-plasma heat sources and proposed an appropriate preheating method for effective machining. Lee and Lee [23] studied cutting force by setting the plasma power and gas flow rate as a machining variable and proposed using $2 \mathrm{~kW}$ of power and $25 \mathrm{l} / \mathrm{min}$ of gas flow rate. Leshock et al. [24] studied heating and operating parameters and systematically analyzed the process control of plasma enhanced machining. They established that PAM reduced the cutting force by $30 \%$ and increased tool life by $40 \%$. Wang et al. [25] studied combinations of traditional turning with cryogenically enhanced machining and plasma enhanced machining. Using the proposed machining method, the cutting force and surface roughness were reduced and tool life was extended. They established that PAM reduced the cutting force and surface roughness by 30 to $50 \%$ and $250 \%$, and increased tool life by $156 \%$.

Most of the studies have focused on the aspects of tool life and surface roughness, however, the effect of spindle speed and depth of cut is not well understood. On the other hand, our paper focused on the effect of each factor (feed rate, spindle speed, and depth of cut on cutting force and surface roughness), optimal machining conditions of PAM, and compared CM with PAM through the analysis of energy efficiency. In this paper, the optimal machining conditions for PAM were analyzed by investigating machining characteristics such as cutting force and surface roughness. The selected factors were feed rate, spindle speed, and depth of cut. The experimental optimal machining conditions were determined using the Taguchi method. The influence of factors on the PAM were analyzed using the Taguchi method. Then, the relative characteristics of the factors were determined through analysis of variance. The optimal PAM machining conditions were analyzed using response optimization. In addition, the suitability of the analysis results were evaluated by comparing the results of the prediction equation and the verification experiment. Finally, the energy efficiency of the PAM was analyzed by comparing the specific cutting energy of the CM and the PAM.

\section{Plasma Assisted Machining}

PAM is a machining method for difficult-to-cut materials that uses a plasma heat source. Figure 1 shows a schematic design of the PAM. The diameter of the heat source was $6 \mathrm{~mm}$, and the plasma heat source precedes ahead of the cutting tool. The cutting tool then cut the preheated part. The cutting tool used was $\varnothing 8 \mathrm{~mm}, 4$ flute, and $70 \mathrm{~mm}$ length flat end-mill, in consideration of the size of the plasma heat source. 


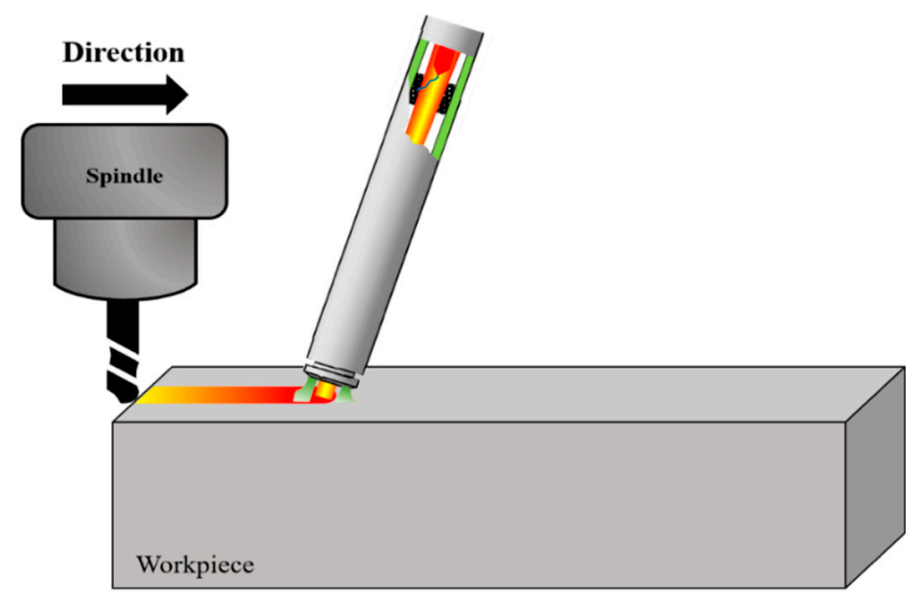

Figure 1. Schematic diagram of the plasma assisted machining (PAM).

The plasma torch was divided into a non-transfer torch and a transfer torch, according to the generation method. The non-transfer torch generates plasma inside the torch, while the transfer torch generates plasma between the workpiece and the torch $[18,19]$. In this study, the non-transfer torch was used. Figure 2 shows the design of a non-transfer torch.

\section{Non transferred plasma arc}

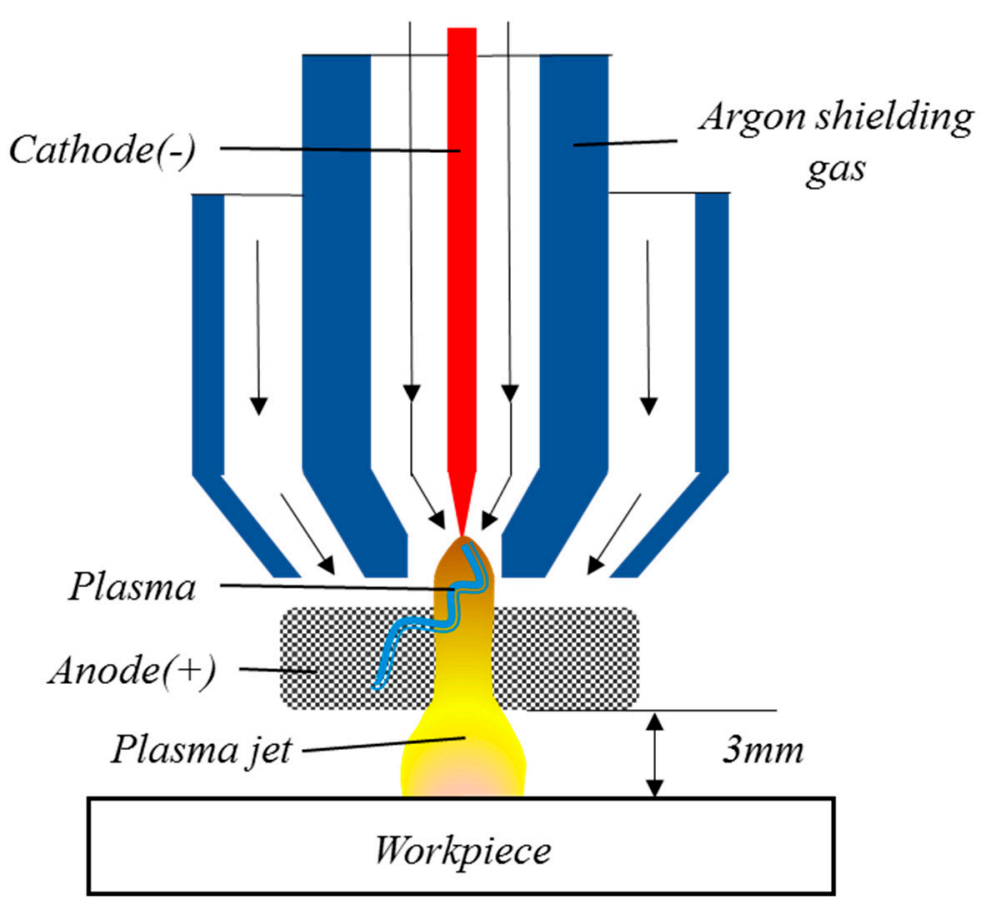

Figure 2. Design of a non-transfer plasma torch.

\section{Finite Element Method}

\subsection{Thermal Analysis}

The material used was Ti-6Al-4V Alpha-Beta, which is widely employed in aviation and automobile parts. First, a plasma heating analysis of the titanium was performed. The thermal analysis was required to select the effective depth of cut. The preheating temperature was selected considering the tensile strength of Ti-6Al-4V, according to temperature. The thermal analysis was undertaken using the ANSYS work-bench where a transient thermal analysis was performed. Figure 3 shows the thermal 
analysis model used in this study. The material size was $15 \mathrm{~mm}$ x $15 \mathrm{~mm}$ x $60 \mathrm{~mm}$ (Thickness $\times$ Width $\times$ Length). The mesh was applied using the hex dominant method for the thermal analysis. The mesh size of the heated zone was divided by $0.5 \mathrm{~mm}$ for accurate analysis, and the other parts were divided by $1 \mathrm{~mm}$. The diameter of the plasma heat source was $6 \mathrm{~mm}$. The number of nodes and elements were 69,681 and 203,045.

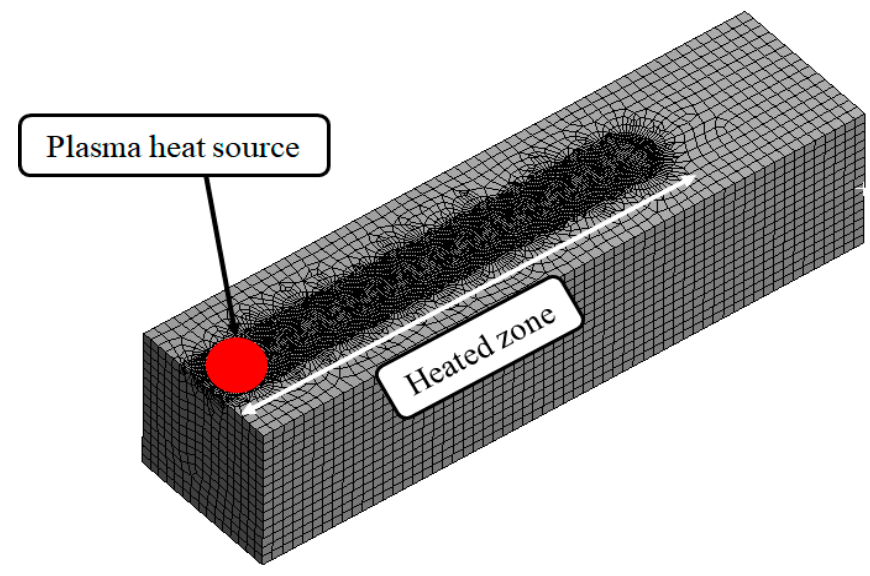

Figure 3. Analysis model.

The heat transfer equations and boundary conditions used in the plasma analysis are shown in Equations (1) and (2) [23,26].

$$
\frac{\partial}{\partial_{x}}\left(k \frac{\partial T}{\partial x}\right)+\frac{\partial}{\partial y}\left(k \frac{\partial T}{\partial y}\right)+\frac{\partial}{\partial z}\left(k \frac{\partial T}{\partial z}\right)+\dot{Q}=\rho C_{\rho} \frac{\partial T}{\partial t}
$$

In Equation (1), $T, t, k, C_{\rho}, \rho$, and $\dot{Q}$ represent the temperature, time, thermal conductivity, specific heat, density, and heat generation rate, respectively.

$$
-k \frac{\partial T}{\partial z}=q(x, y)-h\left(T-T_{O}\right)
$$

In Equation (2), $q$ and $h$ represent the heat flux and heat transfer coefficient.

\subsection{Results of Analysis}

Table 1 shows the chemical composition of Ti-6Al-4V. The heat flow conditions were applied to the plasma heat source. The convection condition of workpiece was applied to $5 \mathrm{~W} / \mathrm{m}^{2} \cdot{ }^{\circ} \mathrm{C}$, which was equal to the air condition. The density of Ti-6Al-4V was applied to $4.5 \mathrm{~g} / \mathrm{cm}^{3}$. The specific heat and thermal conductivities of the Ti-6Al-4V are shown in Figure 4. The tensile strength of Ti-6Al-4V decreased rapidly by $49 \%$ to $64 \%$ when compared to the strength of the room temperature, in the range of about 450 to $600{ }^{\circ} \mathrm{C}[27,28]$. The preheating temperature was selected considering the tensile strength of Ti-6Al-4V, according to temperature. Therefore, the preheating temperature on the surface was set to $600{ }^{\circ} \mathrm{C}$ and depth of cut was set to $0.5 \mathrm{~mm}$, considering the tensile strength which sharply decreased at $450{ }^{\circ} \mathrm{C}$. In this thermal analysis, the feed rate was set to $250 \mathrm{~mm} / \mathrm{min}$, the fastest among the feed rate levels. Since the heat effect was lowest at a feed rate of $250 \mathrm{~mm} / \mathrm{min}$, the thermal analysis was performed at a feed rate of $250 \mathrm{~mm} / \mathrm{min}$ to ensure the fairness of the experiment. Figure 5 shows the temperature distribution and depth of cut for a preheating temperature of $600{ }^{\circ} \mathrm{C}$ and a feed rate of $250 \mathrm{~mm} / \mathrm{min}$. As a result of the thermal analysis, the depth of cut was set to be about $0.5 \mathrm{~mm}$. 
Table 1. Chemical composition of Ti-6Al-4V (wt.\%).

\begin{tabular}{cccccccc}
\hline $\mathbf{T i}$ & $\mathbf{A 1}$ & $\mathbf{V}$ & $\mathbf{F e}$ & $\mathbf{O}$ & $\mathbf{C}$ & $\mathbf{N}$ & $\mathbf{H}$ \\
\hline $88.02 \%$ & $6.75 \%$ & $4.5 \%$ & $0.4 \%$ & $0.2 \%$ & $0.08 \%$ & $0.03 \%$ & $0.01 \%$ \\
\hline
\end{tabular}

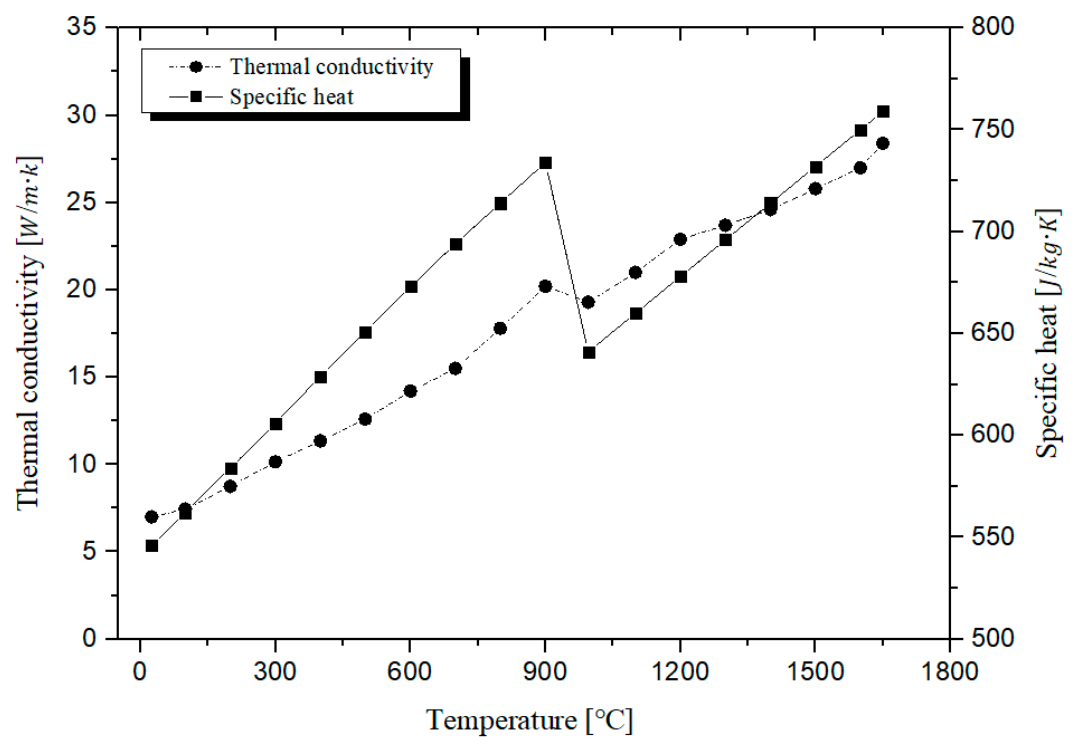

Figure 4. Thermal conductivity and specific heat of Ti-6Al-4V $[27,28]$.

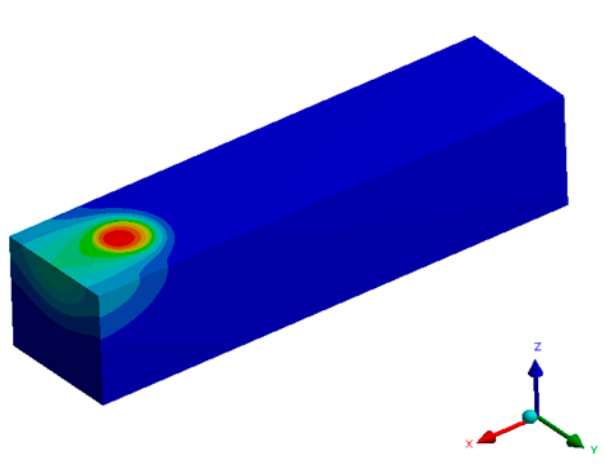

(a)

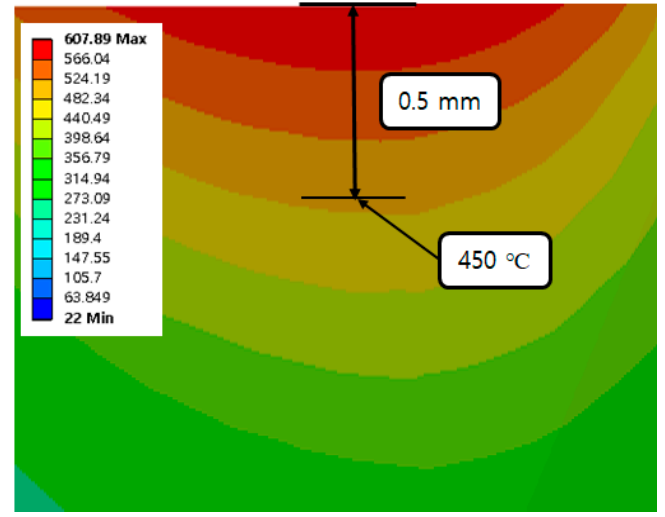

(b)

Figure 5. The thermal analysis results of a preheating temperature of $600{ }^{\circ} \mathrm{C}$ and a feed rate of $250 \mathrm{~mm} / \mathrm{min}$, (a) The temperature distribution of workpiece; (b) Section view in the $\mathrm{x}-\mathrm{z}$ plane.

\section{Experiment}

\subsection{Experiment Setup}

Figure 6 shows the experimental setup used in the PAM. In this experiment, the machining experiment was performed using a 5-axis machining center (Hyundai WIA, Hi-V560M, Changwon, Korea) and the torch (PLASNIX, IGBT, Incheon, Korea) used to generate the plasma was mounted on the right side of the spindle. The plasma torch was a non-transfer type torch and argon gas was used. In addition, a coolant device was installed to prevent the plasma torch from being damaged by heat at a high temperature. A dynamometer (Kistler, 9257B, Winterthur, Switzerland) was installed to measure the cutting force. The preheating temperature of the material surface was measured with a pyrometer (Dr. Mergenthaler GmbH \& Co. KG, LPC03, Neu-Ulm, Germany). The workpiece used was Ti-6Al-4V and the cutting tool used was a flat-end mill (WIDIN, ZE324081, Changwon, Korea). 
Additionally, the surface roughness of the workpiece was analyzed using a surface roughness tester (KOSAKA, SEF-3500K, Tokyo, Japan).

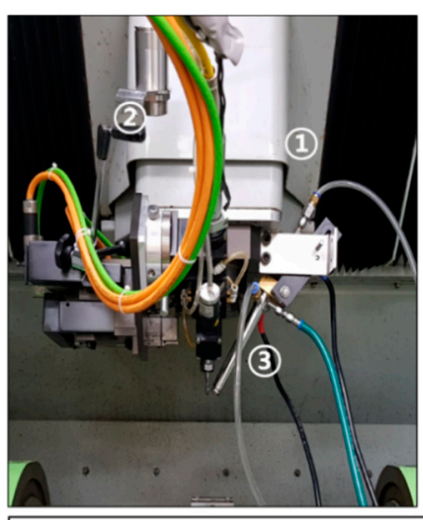

1. 5 axis machining center 4. Flat end mill

2. Pyrometer

3. Plasma torch
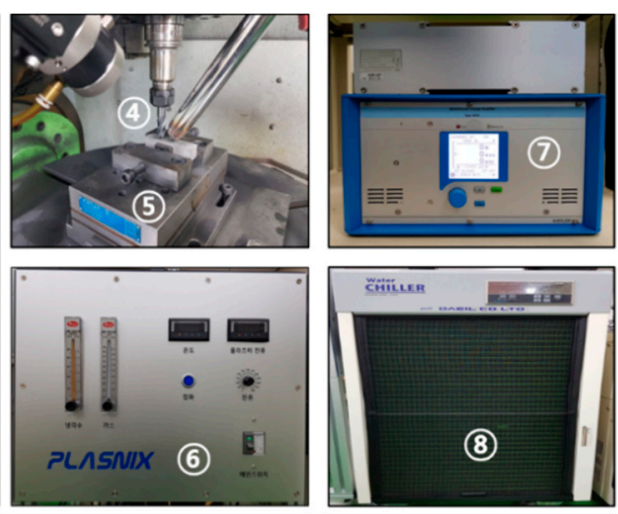

7. Charge amplifier

8. Chiller device

5. Dynamometer

6. Plasma controller

Figure 6. Experimental setup.

\subsection{Design of Experiments}

In PAM, machining characteristics are affected by various factors. In order to quantitatively understand the influence of the factors on the machining characteristics, the experiments should be carried out after considering all combinations of factors. However, to do so would increase the number of experiments and with high cost and time consumption. Therefore, a small number of experiments were performed using the Taguchi method. The robust design of the Taguchi method allows one to find the large influential factors to control, and minimizes the influence of noise by maximizing the influence of these factors. The Taguchi method uses the signal to noise ratio ( $\mathrm{S} / \mathrm{N}$ ratio) to evaluate the fluctuation in product quality in the parameter design [28-34].

In this experiment, the Taguchi method was applied using MINITAB. The PAM evaluation characteristics were analyzed in terms of cutting force and surface roughness. The cutting force and surface roughness were calculated by using the smaller-the-better characteristic. The experiments were performed using orthogonal arrays by setting controllable machining conditions factors. The signal-to-noise ratio according to the quality characteristic was calculated and a factor indicating the maximum $\mathrm{S} / \mathrm{N}$ ratio was found. The smaller characteristic is shown in Equation (3).

$$
\mathrm{S} / \mathrm{N}=-10 \log \left[\frac{1}{n} \sum_{i=1}^{n} y_{i}^{2}\right]
$$

where $y_{i}$ represents the data obtained from the experiment, and $\mathrm{n}$ represents the number of experiments.

\subsection{Machining Condition}

The signal-to-noise ratio according to the quality characteristic was calculated and the factor indicating the maximum $\mathrm{S} / \mathrm{N}$ ratio was found. The feed rate, spindle speed, and depth of cut were set as the control factors in this study. The feed rate levels were set at $50 \mathrm{~mm} / \mathrm{min}, 150 \mathrm{~mm} / \mathrm{min}$, and $250 \mathrm{~mm} / \mathrm{min}$ and the spindle speed levels were set at $2000 \mathrm{rpm}, 7000 \mathrm{rpm}$, and 12,000 rpm.

When using a general cutting tool recommended by WIDIN Co. Ltd for Ti-6Al-4V, it is normally used at a feed rate of $50 \mathrm{~mm} / \mathrm{min}$ and a spindle speed of $2000 \mathrm{rpm}$. In order to experiment with high speed machining to improve productivity efficiency, the feed rate and spindle speed were set at $250 \mathrm{~mm} / \mathrm{min}$ and $12,000 \mathrm{rpm}$. The levels of the depth of cut were determined by dividing the effective 
depth of cut into three parts based on the thermal analysis result. The gas flow rate and the torch angle, which are fixed parameters, were defined using the optimal values obtained in the previous study [23]. Table 2 shows the PAM machining conditions. The three factors and the three levels were applied in this experiment. Table 3 shows the $L_{9}\left(3^{4}\right)$ table of orthogonal arrays.

Table 2. Machining conditions.

\begin{tabular}{ccccc}
\hline \multirow{2}{*}{ Factors } & Code & \multicolumn{3}{c}{ Level } \\
\cline { 3 - 5 } & & $\mathbf{1}$ & $\mathbf{2}$ & $\mathbf{3}$ \\
\hline Feed rate $(\mathrm{mm} / \mathrm{min})$ & $\mathrm{A}$ & 50 & 150 & 250 \\
Spindle speed $(\mathrm{rpm})$ & $\mathrm{B}$ & 2000 & 7000 & 12,000 \\
Depth of cut $(\mathrm{mm})$ & $\mathrm{C}$ & 0.2 & 0.35 & 0.5 \\
& \multicolumn{4}{c}{ Gas flow rate: $251 / \mathrm{min}$} \\
Constant factors & Trerch angle: $60^{\circ}$ \\
& \multicolumn{3}{c}{ Preheating temperature: $600^{\circ} \mathrm{C}$} \\
\hline
\end{tabular}

Table 3. $L_{9}\left(3^{4}\right)$ Table of orthogonal arrays.

\begin{tabular}{cccc}
\hline Run Order & Feed Rate (A)(mm/min) & Spindle Speed (B)(rpm) & Depth of Cut (C)(mm) \\
\hline 1 & 1 & 1 & 1 \\
2 & 1 & 2 & 2 \\
3 & 1 & 3 & 3 \\
4 & 2 & 1 & 2 \\
5 & 2 & 2 & 3 \\
6 & 2 & 3 & 1 \\
7 & 3 & 1 & 3 \\
8 & 3 & 2 & 1 \\
9 & 3 & 3 & 2 \\
\hline
\end{tabular}

\subsection{Measurement}

Cutting force and surface roughness were measured as shown as Figure 7. X (feed direction) and $\mathrm{Y}$ (normal direction) axis cutting force was measured within 10 20 s considering the entry of the tool and was calculated by Equation (4).

$$
\text { Mean of resultant cutting force }=\frac{1}{n} \sum_{k=1}^{n} \sqrt{F_{x k}^{2}+F_{y k}^{2}}
$$

where $\mathrm{n}$ is the number of time intervals equal to 10,000 .

$\mathrm{F}_{\mathrm{x}}$ is a feed direction force and $\mathrm{F}_{\mathrm{y}}$ is a normal direction force. The confidence interval was obtained by calculating the standard deviation between the measured cutting forces and average cutting force by three repeated experiments. The surface roughness was also measured three times. 


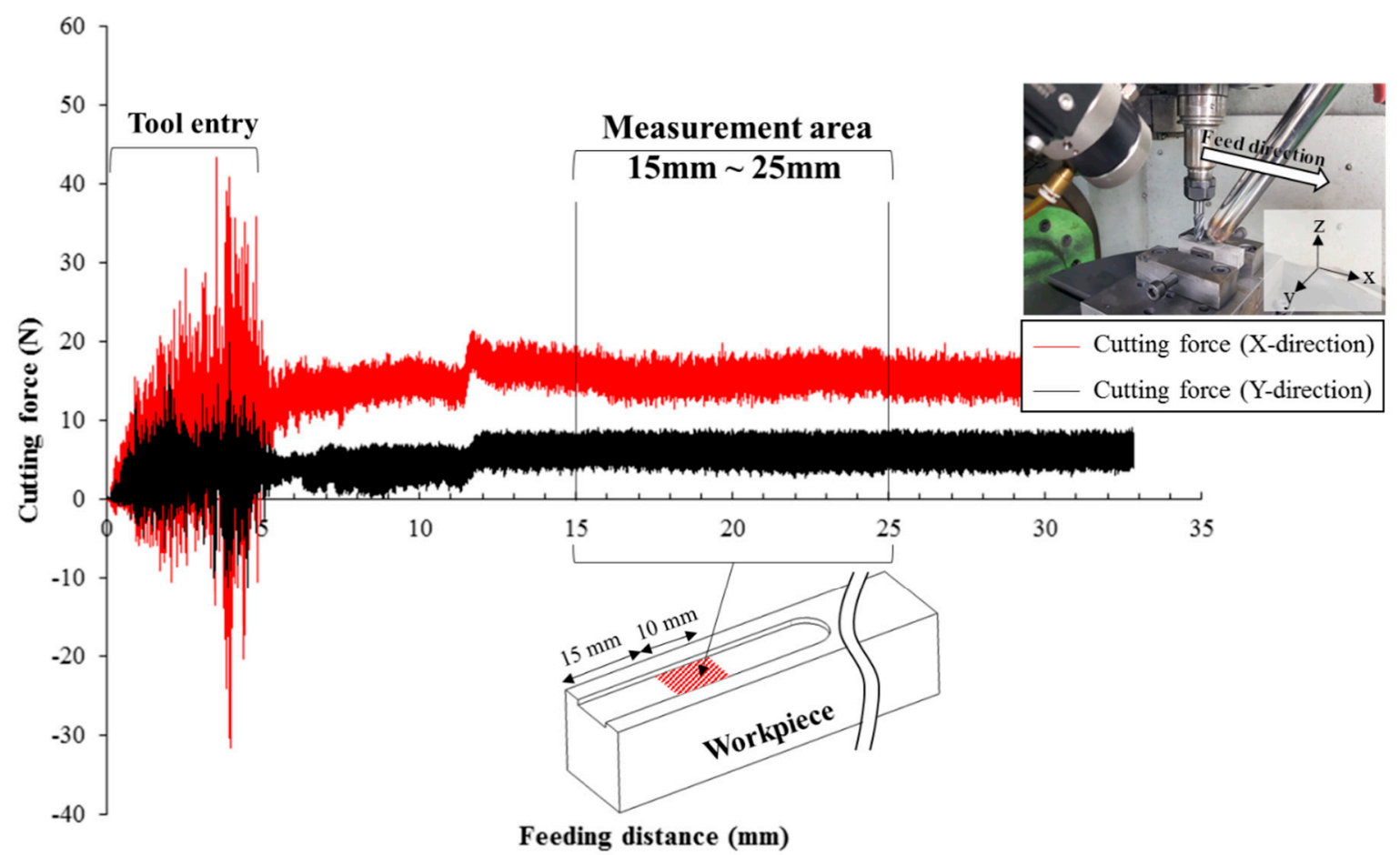

Figure 7. Measurement area of the cutting force and surface roughness.

\section{Results and Discussion}

\subsection{Main Effect}

As indicated in the designated orthogonal array table, nine different PAM experiments were conducted. Table 4 shows the results, obtained by calculating the average values of the experiments. Figure 8 shows the main effect of the $\mathrm{S} / \mathrm{N}$ ratio on the cutting force. The factor that had the greatest influence on the cutting force was feed rate, and the next was depth of cut and spindle speed, as shown in Table 5. Figure 9 shows the main effect of the $\mathrm{S} / \mathrm{N}$ ratio on surface roughness. The factor that had the greatest influence on surface roughness was feed rate, and the next was depth of cut and spindle speed, as seen in Table 6.

The lowest cutting force was confirmed at feed rate A and level 1 (A1), the spindle speed B and level 3 (B3), and the depth of cut $C$ and level 1 (C1) were used. The lowest surface roughness was confirmed when feed rate A and level 1 (A1), spindle speed B and level 3 (B3), and depth of cut C and level (C1) were used.

Table 4. $L_{9}\left(3^{4}\right)$ Experimental results of the cutting force and surface roughness.

\begin{tabular}{cccccc}
\hline Exp. No. & $\begin{array}{c}\text { Feed Rate } \\
(\mathbf{m m} / \mathbf{m i n})\end{array}$ & $\begin{array}{c}\text { Spindle Speed } \\
(\mathbf{r p m})\end{array}$ & $\begin{array}{c}\text { Depth of Cut } \\
(\mathbf{m m})\end{array}$ & $\begin{array}{c}\text { Cutting Force } \\
(\mathbf{N})\end{array}$ & $\begin{array}{c}\text { Surface } \\
\text { Roughness }(\boldsymbol{\mu} \mathbf{m})\end{array}$ \\
\hline 1 & 50 & 2000 & 0.2 & 18.548 & 0.128 \\
2 & 50 & 7000 & 0.35 & 13.61 & 0.131 \\
3 & 50 & 12,000 & 0.5 & 26.418 & 0.171 \\
4 & 150 & 2000 & 0.35 & 33.481 & 0.169 \\
5 & 150 & 7000 & 0.5 & 49.648 & 0.178 \\
6 & 150 & 12,000 & 0.2 & 17.148 & 0.115 \\
7 & 250 & 2000 & 0.5 & 70.188 & 0.287 \\
8 & 250 & 7000 & 0.2 & 37.485 & 0.241 \\
9 & 250 & 12,000 & 0.35 & 42.484 & 0.218 \\
\hline
\end{tabular}


Table 5. Response table mean $\mathrm{S} / \mathrm{N}$ ratio for the cutting force, according to the machining conditions.

\begin{tabular}{cccc}
\hline Level & Feed Rate $(\mathbf{m m} / \mathbf{m i n})$ & Spindle Speed (rpm) & Depth of Cut (mm) \\
\hline 1 & -25.49 & -30.93 & -27.42 \\
2 & -29.94 & -29.36 & -28.58 \\
3 & -33.66 & -28.81 & -33.09 \\
Delta & 8.16 & 2.12 & 5.68 \\
Rank & 1 & 3 & 2 \\
\hline
\end{tabular}

Table 6. Response table mean S/N ratio for the surface roughness, according to the machining conditions.

\begin{tabular}{cccc}
\hline Level & Feed Rate $(\mathbf{m m} / \mathbf{m i n})$ & Spindle Speed $(\mathbf{r p m})$ & Depth of Cut $(\mathbf{m m})$ \\
\hline 1 & 16.95 & 14.71 & 16.33 \\
2 & 16.41 & 15.00 & 15.44 \\
3 & 12.14 & 15.79 & 13.72 \\
Delta & 4.81 & 1.07 & 2.61 \\
Rank & 1 & 3 & 2 \\
\hline
\end{tabular}

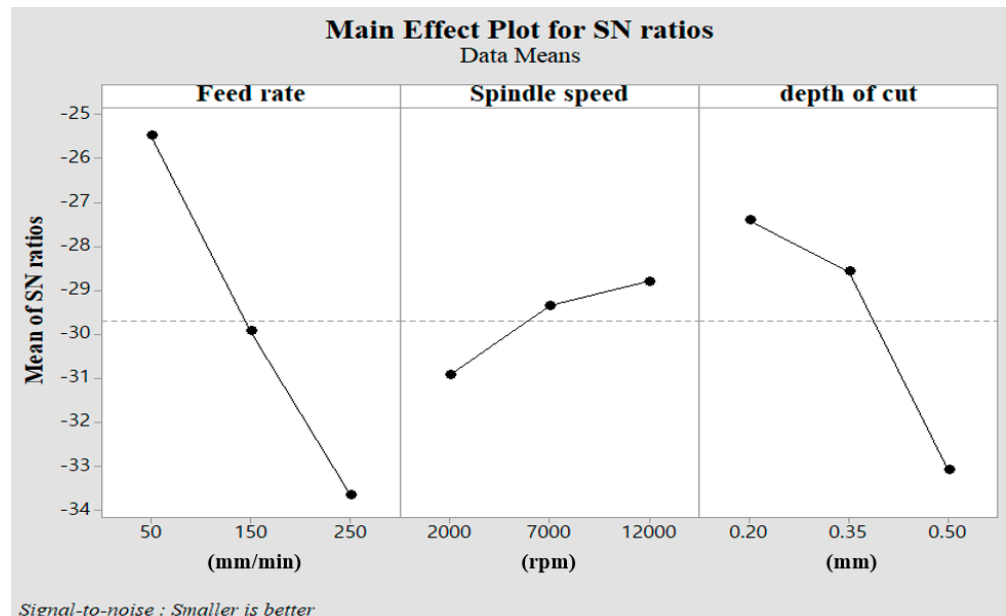

Figure 8. Main effect of the $\mathrm{S} / \mathrm{N}$ ratio on cutting force.

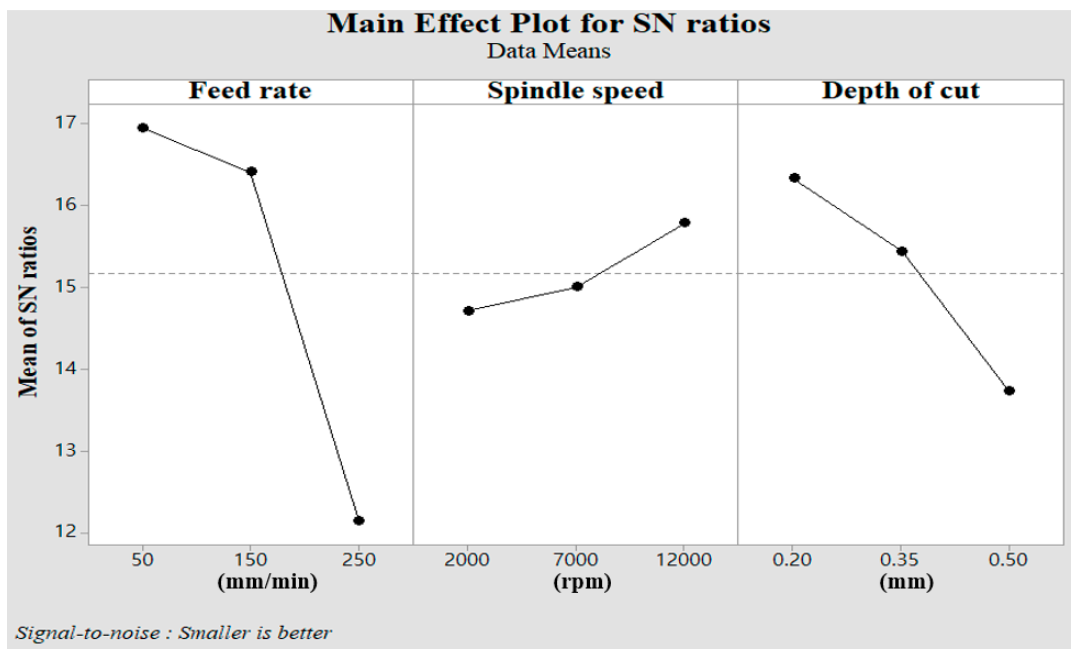

Figure 9. Main effect of the $\mathrm{S} / \mathrm{N}$ ratio on surface roughness. 


\subsection{Analysis of Variance}

An analysis of variance (ANOVA) was conducted to confirm the relative characteristics of the factors. Tables 7 and 8 show the results of the ANOVA regarding cutting force and surface roughness. In the results, feed rate was the most influential factor on cutting force. The contribution of factors to the cutting force were approximately $54.15 \%$ for the feed rate, $7.9 \%$ for the spindle speed, and $36.79 \%$ for the depth of cut. Similarly, the feed rate was the most influential factor in the surface roughness. The contribution of factors to the surface roughness were approximately $77.24 \%$ for the feed rate, $4.12 \%$ for the spindle speed, and $16.25 \%$ for the depth of cut.

Table 7. Analysis of variance for the cutting force.

\begin{tabular}{cccccc}
\hline Factors & $\begin{array}{c}\text { Degree of } \\
\text { Freedom }\end{array}$ & $\begin{array}{c}\text { Sum of } \\
\text { Squares }\end{array}$ & $\begin{array}{c}\text { Mean of } \\
\text { Squares }\end{array}$ & F Ratio & $\begin{array}{c}\text { Contribution } \\
\mathbf{( \% )}\end{array}$ \\
\hline Feed rate & 2 & 1399.34 & 699.67 & 699.67 & 54.15 \\
Spindle speed & 2 & 204.11 & 102.05 & 102.05 & 7.9 \\
Depth of cut & 2 & 950.78 & 475.39 & 475.39 & 36.79 \\
Error & 2 & 30.20 & 15.01 & & 1.16 \\
Total & 8 & 2584.25 & & & 100.00 \\
\hline
\end{tabular}

Table 8. Analysis of variance for the surface roughness.

\begin{tabular}{cccccc}
\hline Factors & $\begin{array}{c}\text { Degree of } \\
\text { Freedom }\end{array}$ & $\begin{array}{c}\text { Sum of } \\
\text { Squares }\end{array}$ & $\begin{array}{c}\text { Mean of } \\
\text { Squares }\end{array}$ & F ratio & $\begin{array}{c}\text { Contribution } \\
(\%)\end{array}$ \\
\hline Feed rate & 2 & 0.02 & 0.01 & 32.22 & 77.24 \\
Spindle speed & 2 & 0.001 & 0.0005 & 1.72 & 4.12 \\
Depth of cut & 2 & 0.004 & 0.002 & 6.78 & 16.25 \\
Error & 2 & 0.0006 & 0.0003 & & 2.4 \\
Total & 8 & 0.026 & & & 100.00 \\
\hline
\end{tabular}

\subsection{Response Optimization}

A response optimization analysis was performed using the results of the Taguchi method. The response optimization helps to distinguish the combinations of factors that optimize a series of responses in common. This is helpful when considering the effect of several factors on the response. Tables 9 and 10 show the response optimization and the results of the response optimization. In the results, the feed rate, the spindle speed and the depth of cut were analyzed at $50 \mathrm{~mm} / \mathrm{min}, 12,000 \mathrm{rpm}$, and $0.2 \mathrm{~mm}$. Desirability was confirmed at 1 .

Table 9. Response optimization.

\begin{tabular}{cccccc}
\hline Parameter & Goal & Target & Upper & Weight & Importance \\
\hline $\begin{array}{c}\text { Cutting force } \\
\text { Surface }\end{array}$ & Minimum & $13.610 \mathrm{~N}$ & $70.188 \mathrm{~N}$ & 1 & 1 \\
roughness & Minimum & $0.115 \mu \mathrm{m}$ & $0.287 \mu \mathrm{m}$ & 1 & 1 \\
\hline
\end{tabular}

Table 10. Result of the response optimization.

\begin{tabular}{cccccc}
\hline $\begin{array}{c}\text { Feed Rate } \\
(\mathbf{m m} / \mathbf{m i n})\end{array}$ & $\begin{array}{c}\text { Spindle Speed } \\
(\mathbf{r p m})\end{array}$ & $\begin{array}{c}\text { Depth of Cut } \\
(\mathbf{m m})\end{array}$ & $\begin{array}{c}\text { Cutting Force } \\
\text { Optimization } \\
\text { Plot (N) }\end{array}$ & $\begin{array}{c}\text { Surface } \\
\text { Roughness } \\
\text { Optimization } \\
\text { Plot }(\mu \mathrm{m})\end{array}$ & Desirability \\
\hline 50 & 12,000 & 0.2 & 4.6 & 0.108 & 1 \\
\hline
\end{tabular}




\subsection{Verification Experiment of and Prediction Equations}

Next, verification experiments were conducted to evaluate the suitability of the analysis results. The prediction equations of the cutting force and the surface roughness are shown in Equations (5) and (6).

$$
\begin{gathered}
F_{C}=34.50-\quad 14.98(F 50)-0.58(F 150)+15.55(F 250)+6.24(S 2000) \\
-0.92(S 7000)-5.32(S 12000)-9.61(D 0.2) \\
-4.64(D 0.35)+14.25(D 0.5) \\
F_{S}=0.182-\quad 0.038(F 50)-0.028(F 150)+0.066(F 250) \\
+0.012(S 2000)-0.001(S 7000)-0.014(S 12000) \\
-0.02(D 0.2)-0.009(D 0.35)+0.03(D 0.5)
\end{gathered}
$$

where $F_{C}$ represents the cutting force, while $F_{S}$ represents the surface roughness.

Table 11 show the machining conditions of the verification experiments. The five experiments were conducted by randomly adding the levels of the factors including the optimal machining conditions (Exp. No. 1), as specified in Table 11. Figure 10 compares the results of the prediction equation and the verification experiments for cutting force. The maximum error rate was verified as approximately $19.1 \%$. Figure 11 shows a comparison of the results of the prediction equation and the verification experiments for surface roughness. The maximum error rate was approximately $6.04 \%$.

Table 11. Machining conditions of the verification experiments.

\begin{tabular}{cccc}
\hline Exp. No. & Feed Rate $(\mathbf{m m} / \mathbf{m i n})$ & Spindle Speed $(\mathbf{r p m})$ & Depth of Cut $(\mathbf{m m})$ \\
\hline 1 & 50 & 12,000 & 0.2 \\
2 & 150 & 7000 & 0.2 \\
3 & 150 & 12,000 & 0.35 \\
4 & 250 & 7000 & 0.5 \\
5 & 250 & 12,000 & 0.5 \\
\hline
\end{tabular}

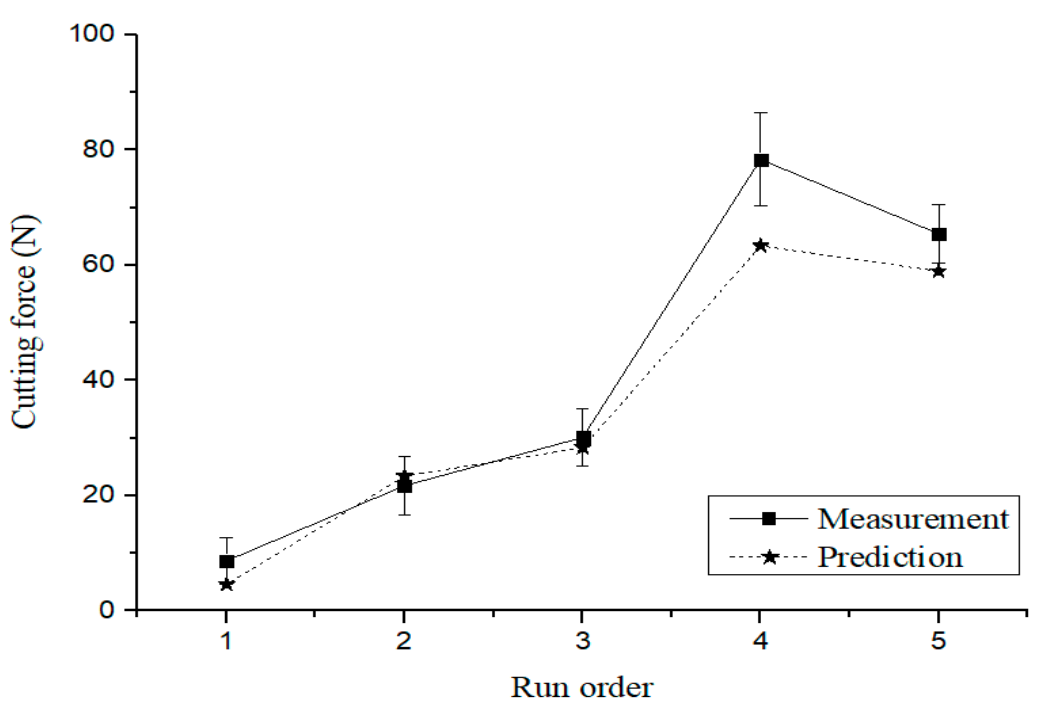

Figure 10. Comparison of the results of the prediction equation and the verification experiments for the cutting force. 


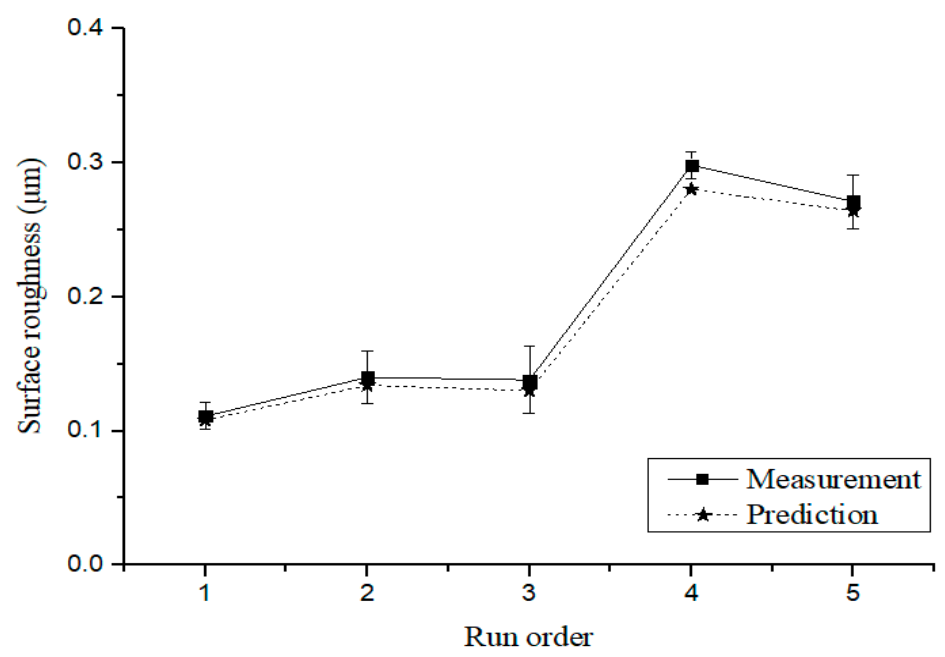

Figure 11. Comparison of the results of the prediction equation and the verification experiments for the surface roughness.

\subsection{Specific Cutting Energy}

The specific cutting energy is the energy required to cut a unit volume of material per unit time. In this research, the specific cutting energy was used to verify the energy efficiency of the CM and PAM. The specific cutting energy, $U$, is defined as [28]

$$
\mathrm{U}=\frac{F_{t} \times V}{M R R}
$$

In Equation (7), $F_{t}, \mathrm{~V}$, and MRR represent the cutting force, the cutting speed, and the material removal rate, respectively. The material removal rate, MRR, is defined as [28]

$$
\mathrm{MRR}=\mathrm{F} \times \mathrm{W} \times \mathrm{D}
$$

In Equation (8), F, W, and D, represent the feed rate, the width of cut, and the depth of cut.

Figure 12 shows the results for specific cutting energy in the CM and PAM. The specific cutting energy for PAM decreased by approximately $60.2 \%$ compared to the CM. Therefore, it can be seen that PAM increased the specific cutting energy efficiency.

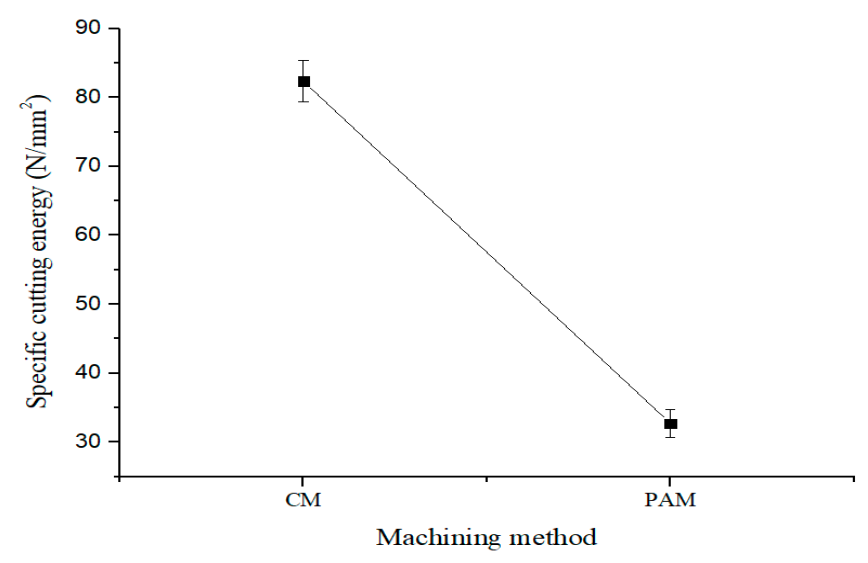

Figure 12. Result of specific cutting energy in the CM and PAM.

\section{Conclusions}

In this study, the optimal machining conditions for plasma assisted machining of Ti-6Al-4V materials were studied. Thermal analysis was performed to select the effective depth of cut of Ti-6Al-4V. 
The optimal machining conditions for PAM were determined by DOE, and the evaluation characteristics were analyzed by cutting force and surface roughness. The prediction equations for cutting force and surface roughness were obtained using regression analysis.

The conclusions of this study are as follows.

(1) The preheating temperature and the depth of cut were determined as $600{ }^{\circ} \mathrm{C}$ and $0.5 \mathrm{~mm}$, respectively. These values were determined by thermal analysis and considered the tensile strength change of Ti-6Al-4V by temperature.

(2) The relative contributions of the factors were analyzed through the analysis of variance. Feed rate had the most influence on cutting force and surface roughness.

(3) Prediction equation was verified by verification experiments. The optimal machining conditions for PAM were determined as a feed rate of $50 \mathrm{~mm} / \mathrm{min}$, spindle speed of $12,000 \mathrm{rpm}$, and depth of cut of $0.2 \mathrm{~mm}$.

(4) In optimal machining conditions, the cutting force of $\mathrm{CM}$ and PAM was $21.84 \mathrm{~N}$ and $8.68 \mathrm{~N}$, respectively. The cutting force of PAM was decreased by $60.2 \%$ when compared to CM. In addition, the surface roughness of CM and PAM was $0.376 \mathrm{um}$ and $0.111 \mathrm{um}$, respectively. The surface roughness of PAM was improved by $70.47 \%$ when compared to $\mathrm{CM}$.

(5) The energy efficiency of PAM was analyzed by comparing the specific cutting energy. The specific cutting energy of PAM was $32.9 \mathrm{~N} / \mathrm{mm}^{2}$. The energy efficiency of PAM improved to above $60.26 \%$ when compared to CM.

Author Contributions: Conceptualization, Y.-H.L.; Data curation, Y.-H.L.; Formal analysis, Y.-H.L.; Funding acquisition, C.-M.L.; Supervision, C.-M.L.; Writing—original draft, Y.-H.L.; Writing—review \& editing, Y.-H.L.

Funding: This work was supported by the National Research Foundation of Korea (NRF) grant funded by the Korea government (MSIT) (No. 2019R1A2B5B03070206).

Conflicts of Interest: The authors declare no conflicts of interest.

\section{References}

1. Brecher, C.; Rosen, C.J.; Emonts, M. Laser-assisted milling of advanced materials. Phys. Procedia 2010, 5, 259-272. [CrossRef]

2. Wiedenmann, R.; Liebl, S.; Zaeh, M.F. Influencing factors and workpiece's microstructure in laser-assisted milling of titanium. Phys. Procedia 2012, 39, 265-276. [CrossRef]

3. Shelton, J.A.; Shin, Y.C. Comparative evaluation of laser-assisted micro-milling for AISI 316, AISI 422, TI-6Al-4V and Inconel 718 in a side-cutting configuration. J. Micromech. Microeng. 2010, 20, 075012. [CrossRef]

4. Lee, C.M.; Kim, D.H.; Baek, J.T.; Kim, E.J. Laser assisted milling device, A review. Int. J. Precis. Eng. Manuf. Green Technol. 2016, 3, 199-208. [CrossRef]

5. Jeon, Y.H.; Lee, C.M. Current research trend on laser assisted machining. Int. J. Precis. Eng. Manuf. 2012, 13, 311-317. [CrossRef]

6. Tian, Y.; Shin, Y.C. Thermal modeling for laser-assisted machining of silicon nitride ceramics with complex features. J. Manuf. Sci. Eng. 2005, 128, 425-434. [CrossRef]

7. Wiedenmann, R.; Zaeh, M.F. Laser-assisted milling_Process modeling and experimental validation. CIRP J. Manuf. Sci. Technol. 2015, 8, 70-77. [CrossRef]

8. Kashani, M.M.; Movahhedy, M.R.; Ahmadian, M.T.; Razavi, R.S. Analytical prediction of the temperature field in laser assisted machining. Procedia CIRP 2016, 46, 575-578. [CrossRef]

9. Navas, V.G.; Arriola, I.; Gonzalo, O.; Leunda, J. Mechanisms involved in the improvement of Inconel 718 machinability by laser assisted machining (LAM). Int. J. Mach. Tools Manuf. 2013, 74, 19-28. [CrossRef]

10. Leopardi, G.; Tagliaferri, F.; Rüger, C.; Dix, M. Analysis of laser assisted milling (LAM) of Inconel 718 with Ceramic Tools. Procedia CIRP 2015, 33, 514-519. [CrossRef]

11. Ito, Y.; Ueki, M.; Kizaki, T.; Sugita, N.; Mitsuichi, M. Precision cutting of glass by laser-assisted machining. Procedia Manuf. 2017, 7, 240-245. [CrossRef] 
12. Ito, Y.; Kizaki, T.; Shinomoto, R.; Ueki, M.; Sugita, N.; Mitsuichi, M. High-efficiency and precision cutting of glass by selective laser-assisted milling. Precis. Eng. 2017, 47, 498-507. [CrossRef]

13. Research report of the National Research Foundation of Korea (NRF). A New Conceptual 3-Dimensional Laser Assisted Machining System; NRF: Seoul, Korea, 2016; 2016R1A2A1A05005492.

14. Kim, T.W.; Lee, C.M. A study on the development of milling process for silicon nitride using ball end-mill tools by laser-assisted machining. Int. J. Adv. Manuf. Technol. 2015, 77, 1205-1211. [CrossRef]

15. Lee, C.M.; Woo, W.S.; Kim, D.H.; Oh, W.J.; Oh, N.S. Laser-assisted hybrid processes-A review. Int. J. Precis. Eng. Manuf. 2016, 17, 257-267. [CrossRef]

16. Lee, C.M.; Woo, W.S.; Baek, J.T.; Kim, E.J. Laser and arc manufacturing processes-A review. Int. J. Precis. Eng. Manuf. 2016, 17, 973-985. [CrossRef]

17. Lo'pez de Lacalle, L.N.; Sanchez, J.A.; Lamikiz, A.; Celaya, A. Plasma assisted milling of heat-resistant superalloys. J. Manuf. Sci. Eng. 2004, 126, 274-285. [CrossRef]

18. Moon, S.H.; Lee, C.M. A study on the machining characteristics using plasma assisted machining of AISI 1045 and Inconel 718. Int. J. Mech. Sci. 2018, 142, 595-602. [CrossRef]

19. Kttagawa, T.; Maekawa, K. Plasma hot machining for new engineering materials. Wear 1990, 139, $251-267$. [CrossRef]

20. Lee, Y.H.; Khulan, E.; Lee, C.M. A basic study on the thermal and machining characteristic of inclined workpiece according to the torch angle in plasma assisted machining. Proceed KSPE Autumn Conf. 2017, $12,86-87$.

21. Kim, J.H.; Jung, H.I.; Lee, C.M. An analytical study on the preheating effect of workpieces with cylindrical shape in plasma assisted machining. Proceed. KSPE Autumn Conf. 2017, 12, 93-94.

22. Baek, J.T.; Moon, S.H.; Lee, Y.H.; Lee, C.M. An analytical study on the preheating effect of flat workpiece for laser-plasma assisted machining. Proceed. KSPE Autumn Conf. 2016, 10, 236.

23. Lee, C.M.; Lee, Y.H. A study on the effect of gas flow rate and power in plasma assisted machining. J. Korean Soc. Precis. Eng. 2018, 35, 603-608. [CrossRef]

24. Leshock, C.E.; Kim, J.N.; Shin, Y.C. Plasma enhanced machining of Inconel 718, modeling of workpiece temperature with plasma heating and experimental results. Int. J. Mach. Tools Manuf. 2001, 41, 877-897. [CrossRef]

25. Wang, Z.Y.; Rajurkar, K.P.; Fan, J.; Lei, S.; Shin, Y.C.; Petrescu, G. Hybrid machining of Inconel 718. Int. J. Mach. Tools Manuf. 2003, 43, 1391-1396. [CrossRef]

26. Kim, D.H.; Lee, C.M. A study of cutting force and preheating-temperature prediction for laser-assisted milling of Inconel 718 and AISI 1045 steel. Int. J. Heat Mass Transf. 2014, 71, 264-274. [CrossRef]

27. Sim, M.S.; Lee, C.M. Determination of optimal laser power according to the tool path inclination angle of a titanium alloy workpiece in laser-assisted machining. Int. J. Adv. Manuf. Technol. 2016, 83, 1717-1724. [CrossRef]

28. Woo, W.S.; Lee, C.M. A study on the optimum machining conditions and energy efficiency of a laser-assisted fillet milling. Int. J. Precis. Eng. Manuf. Green Technol. 2018, 5, 593-604. [CrossRef]

29. Datta, S.; Bandyopadhyay, A.; Pal, P.K. Grey-based taguchi method for optimization of bead geometry in submerged arc bead-on-plate welding. Int. J. Adv. Manuf. Technol. 2008, 39, 1136-1143. [CrossRef]

30. Mohd, A.; Siti, S.; Abdul, F.; Raja, L.; Mohd, H.; Manshoor, B.; Mohd, S.; Mohd, A. Effect of injection moulding machine parameters on the warpage by applying taguchi method. Appl. Mech. Mater. 2014, 699, $20-25$.

31. Liu, J.W.; Jin, J.; Ko, T.J.; Baek, D.K. Study of optimal machining conditions of ultrasonic machining by taguchi's method. Trans. Korean Soc. Mech. Eng. A 2013, 37, 213-218. [CrossRef]

32. Lee, B.Y.; Lee, H.W. Shape optimal design of an automotive pedal arm using the taguchi method. J. Korean Soc. Precis. Eng. 2007, 24, 76-83.

33. Yoo, W.S.; Jin, Q.Q.; Chung, Y.B. A study on the optimization for the blasting process of glass by taguchi method. J. Soc. Korea Ind. Syst. Eng. 2007, 30, 8-14.

34. Chang, C.W.; Kuo, C.P. Evaluation of surface roughness in laser-assisted machining of aluminum oxide ceramics with the Taguchi method. Int. J. Mach. Tools Manuf. 2007, 47, 141-147. [CrossRef]

(C) 2019 by the authors. Licensee MDPI, Basel, Switzerland. This article is an open access article distributed under the terms and conditions of the Creative Commons Attribution (CC BY) license (http://creativecommons.org/licenses/by/4.0/). 